\title{
SOCIAL STUDIES IN THE CROSS THEMATIC INTEGRATED CURRICULUM FOR THE GREEK KINDERGARTEN AND CHILD SOCIALIZATION
}

\author{
Theodoros G. Eleftherakis ${ }^{1}$, Vasileios Oikonomidis ${ }^{2}$, Evaggelia Kalerante ${ }^{3}$ and \\ Andromachi Kaspiri ${ }^{4}$ \\ ${ }^{1,2}$ Department of Pedagogy and Preschool Education, University of Crete \\ ${ }^{3}$ Department of Kindergarten Teachers, University of Western Macedonia \\ ${ }^{4}$ Teacher / Principal of Special Education School
}

DOI: 10.46609/IJSSER.2021.v06i01.012 URL: https://doi.org/10.46609/IJSSER.2021.v06i01.012

\begin{abstract}
The introduction of Social Studies (History, Religion, Social and Political Education, Sociology, Economics) in the Curriculum is considered particularly important since it supports the development of the young people's personality, their social inclusion and it contributes to shaping sensitized and responsible citizens.

The aim of this study is to explore the role of Social Studies (S.S.) in the Cross Thematic Integrated Curriculum (C.T.I.C.)for the Greek Kindergarten on the one hand and to find out how they reinforce child socialization.

An attempt is made to explore, through content analysis, the philosophy, objectives, methods and manners of evaluation of the Curriculum and the C.T.I.C. for the Kindergarten in order to trace the competences related to Social Sciences (S.S.) and their contribution to child personality shaping and socializing. School is considered to be the breeding ground where the main methodological approaches, that is interdisciplinary and experiential, can be conducive to offering basic knowledge and shaping social and political competences towards developing such attitudes and life values that can enable students' democratic socialization.
\end{abstract}

Key words: Socialization, Kindergarten, Cross Thematic Integrated Curriculum, Social Studies

\section{Introduction}

The socialization of the individual, meaning the preparation of a new member to be included in the society, is virtually based on the relationship with the mother, it continues within the climate of family socialization and rises within the school community and school classroom as a process that follows specific and particular goals set by the state. It is carried out by properly trained individuals throughout the first school socialization period, namely the socialization in the first 


\section{International Journal of Social Science and Economic Research}

ISSN: $2455-8834$

Volume:06, Issue:01 "January 2021"

grade of the education system, the community of the Kindergarten (Spodek, 1969; Koutsouvanou, 2002).

As regards the process of school socialization, the introduction of Social Studies in the Curriculumis considered particularly important since it supports the development of the young people's personality, their social inclusion and it contributes to shaping sensitized and responsible citizens (Allen, 1996; Martorella, 1994). Through orientations of studies or the subjects tied to S.S. (History, Religion, Social and Political Education, Sociology, Economics) necessary knowledge is offered to the developing individuals about the historic and cultural identity of their society, while they are also aided to be harmoniously included in it (Jacobs \& Crowley, 2007). Thus, these subjects are conducive to shifting knowledge, attitudes, types of behavior, cultural models, social, political and religious values to the young generation along with shaping new citizens who will either preserve or change the society (Jacobs \& Crowley, 2007).

The positioning of many partial cognitive fields of S.S., mainly History and Religion, as well as the knowledge of the close environment (home, neighborhood, occupations, public transport and Mass Media) is pivotal in all the Curricula of the Greek Kindergarten (Kitsaras, 1998). It is true that all the issues of consideration for the child and their processing in the Kindergarten emanate from the surrounding natural and social environment (D' Addesio et al., 2005; Jacobs \& Crowley, 2007; Dafermou et al., 2006).

The C.T.I.C. 2002-2003 for Kindergarten, particularly what is relevant to Social Studies and, consequently, the students' direct socialization, is particularly incentive and effective. This means that it provides the Kindergarten teacher the possibility, within the flexible space of the Kindergarten in terms of selecting activities, methods and objectives, to orientate all their efforts and activities more easily towards social learning and the development of social, political and emotional competences. Its aim is to reinforce all forms of student intelligence on the one hand and make cognitive and social learning an easier, more functional, invigorating, effective and pedagogical process of joy and creation both for the Kindergarten students and teacher, with the teacher being the driving force within such a productive context.

The aim of this study is to explore the positioning of S.S. in the Cross Thematic Integrated Curriculum for the Greek Kindergarten (M.E.R.A. - P.I., 2002) and how these studies aim at socializing and, generally, developing the children through relevant suggested activities as they are stated in the section of the Anthropogenic environment and Interaction of C.T.I.C. for the Kindergarten. This way, we will be able to find out how, through cross thematic and experiential approach, which is claimed by the Curriculum of the modern Greek school, a more democratic school can be developed which can be the breeding ground for necessary basic knowledge, 


\section{International Journal of Social Science and Economic Research}

ISSN: $2455-8834$

Volume:06, Issue:01 "January 2021"

metacognition, and mainly the basic social, political and emotional competences and skills along with attitudes and life values to enhance young students' democratic socialization. However, the proper implementation of the cross thematic curriculum requires the elimination of difficulties and confinements of a long period in education, teachers, parents and the society. It can be said that although a decade has passed, this issue has not been satisfactorily resolved yet.

\section{The individual's socialization, preschool socialization and educational inequalities}

According to T. Parsons, socialization is a lifelong process in which "the internalization of culture of a specific society" takes place, meaning the society in which an individual is born, grows up and lives. In other words, this is a lifelong process that contributes to shaping their personality through the norms and values systems, through roles and symbols of this society and the deriving possibility to behave, act and assume roles. Through this socialization, the individual shapes acceptable personality and action, which means that they play socially acceptable roles and, this way, they learn to adapt to and be included in the social environment, while they move towards progress andgoals achievement (Parsons, 1964; Nikolaou, 2009:73). T. Parsons contends that this process of internalization - socialization is realized in 5 consecutive phases: the individual internalizes the culture of the society through their relationship with their mother (phase a), through their relationship with their broader family - siblings, father, relatives - (phase b), through their relationship with the school environment - school socialization (phase c), through their relationship with the group of peers and their friendships (phase $d$ ) and, eventually, through their relationship with their occupation - occupational socialization - (phase e) (Nikolaou, 2009: 73-74).

According to Durkheim, the process of socialization takes place through the interaction between the individual and collective consciousness that is the interaction between adults and under-aged, or to put it differently, the encounter between the previous and the next generation resulting in the biological being turning into a socio-cultural being.

According to the social ecological model - framework or the ecological approach of Uri Bronfenbrenner about human development, the children's personality is shaped through their socialization within the different contexts of living, on a daily basis, in the direct environment where they live (micro-systems). These contexts are associated - correlated - between each other in various ways. Thus, there is association / interaction between family and teachers, the relationship between the child's peers and the family etc. (medium systems) who, in their turn, are associated with contexts and institutions (local self-government, community, etc.) in which the child is not present, yet its development is significantly affected by them (outer systems). All these systems are organized on the basis of the dominant beliefs, attitudes and ideologies of the culture (macro-systems), namely the entire culture of the society (Feldman, 2007). 


\section{International Journal of Social Science and Economic Research}

ISSN: $2455-8834$

Volume:06, Issue:01 "January 2021"

The Kindergarten is the first educational grade that welcomes children coming from the family environment which has influenced them through the family phase of socialization by having already shaped the initial child personality with certain behavior and action (Kyridis, 1996).

The social inequalities among families are turned into educational and school inequalities which firstly appear in the Kindergarten and they are due to each family's characteristic features. These are: a) the Structural characteristics of the family: place, cultural capital, socio-economic capital (Bourdieu \&Passeron, 2014, 1993, 1976) and b) the Functional characteristics of the family: relationships (violent, democratic), parental pedagogical style, divorce, single-parent family etc. (Nikolaou, 2009: 155-161).

The modern school, primarily, with its democratic organization, structure and function in all its levels and, secondly, its proper function of all its variables such as curricula, textbooks, teachers, methods, evaluation, educational legislation and institutions and, generally, all its school activities should provide students both the necessary knowledge and the skills, norms, values and life attitudes that could orientate them to a democratic and balanced way of behavior and life.

Hence, as underlined in the Cross Thematic Integrated Curriculum of 2003, the basic knowledge should be offered firstly, followed by metacognition - ways of discovering knowledge and understanding its cognitive functions - and after that by emotional skills - understanding myself: self-confidence, self-image - the social skills - understanding the other: empathy and cooperation - as well as cultural skills - understanding the political functions: political participation, participation in electing and being elected and decision making.

This way, the Kindergarten is perceived as the first supplement of preschool family socialization and education and an initial intervention of the institutionalized preschool education (Zacharenakis, 1991:37; Kyridis, 1996: 93:, 195-210). At the same time, it becomes the primary state institution which is invited to counterbalance the gap of family socialization and reverse the first educational inequalities emerging from Kindergarten students' school performance (Kyridis, 1996:92). Teachers, educational carriers and institutions' sensitization should be as such so that they are not satisfied simply by formally ensuring equality, but, as Husen puts it, they should ensure the equality of outcomes, a fact rather difficult to be realized, yet always desired (Husen, 1975).

\section{Cross Thematic, experiential approach and democracy}

The Cross Thematic approach exists when the processing of various thematic units is emphasized aiming at the holistic understanding of the surrounding world and not merely at serving partial scientific fields. Thus, teaching partial scientific fields is not an end in itself any more. On the contrary, they all contribute to developing deep understanding about the world, 


\section{International Journal of Social Science and Economic Research}

ISSN: $2455-8834$

Volume:06, Issue:01 "January 2021"

while the scientific knowledge is indirectly cultivated. In this sense, the scientific field is formulated as the outcome of an interdisciplinary effort.

Thus, Cross Thematic means the course of school life through processing various thematic units, while interdisciplinary means the manner of approaching thematic units, a kind of synergy of various scientific fields (Chrysafidis, 2009; Sfyroera, 2002; Seefeldt, 2001; Walmsley \& Wing, 2004).

Experiential Pedagogy is a pedagogic philosophy and didactic approach which bases learning on the direct and mediated students' experiences through actions of familiarization, systematic observation and critical analysis to highlight relations, social judgment, decision making and problem solving.

The experiential approach to learning is suggested in contrast to, or to supplement, the perceptive approach to learning. In other words, it is engaged with what is relevant and correlated, learning how to learn, Learning by Doing, Active Learning and Situated Learning that is learning that presupposes activated association with the entire framework in which it takes place. It is the natural consequence of social interaction and co-operation among the members of a community of practice (Chrysafidis, 2006).

It should be noted that the issues emanating from the human and social environment, issues of Social Studies, are mainly offered for projects that are processed by groups of children (D' Addesio et al., 2005).

\section{Social Studies in the Cross Thematic Integrated Curriculum for Kindergarten and the student democratic socialization}

The existing Greek curriculum for Kindergarten was published in 2002, but its implementation commenced during the school year 2006-2007 when the Guide for the Kindergarten was issued (Dafermou et al., 2006), an abetting book distributed by the Ministry of Education to Kindergarten teachers to support them in the implementation of the new curriculum. The Cross Thematic Integrated Curriculum for Kindergarten (M.E.R.A. - P.I., 2002) for the Greek Kindergarten applies the Cross Thematic Curricular Approach (Chrisafidis, 2009) and it consists of five broader cognitive subjects: 1) Child and Language (oral communication, reading, writing and written communication), 2) Child and Mathematics, 3) Child and Environment (Human Environment, Natural Environment), 4) Child, Creation and Expression (Arts, Drama, Physical Education and Music), and 5) Child and Computers.

Our next step isto examine the positioning of Social Studies (S.S.) in the Cross Thematic Integrated Curriculum for Kindergarten by tracing the objectives - pursuits stated in it and the indicative activities suggested for its implementation. Thus, S.S. are part of the third group of 


\section{International Journal of Social Science and Economic Research}

ISSN: $2455-8834$

Volume:06, Issue:01 "January 2021"

planning activities titled: "Child and Environment" and in the sub-group Human Environment and Interaction which is differentiated from the second sub-group Natural Environment and Interaction which includes approaching the knowledge of Natural Sciences (natural phenomena, capacities and characteristics of materials and planets, etc.). In this first group of Human Environment and Interaction the basic concepts of Geography, History, Religion, Social and Political Education are approached along with elements of Environmental Education, Health Education and Traffic Education (Ministry of Education and Religious Affairs - P.I., 2002a:3). It is suggested that all activities, individual and group ones, commence from previous knowledge and children's needs, "activate creativity, exchange of ideas and lead to new knowledge" (Ministry of Education and Religious Affairs -P.I., 2002a:3). The issues should trigger children's interests as they choose ways, materials and means to study each theme. Thus, facts, phenomena, concepts and processes under examination within the context of S.S. are approached in a Cross Thematic framework that is through various themes. Each theme pertaining to S.S. can possibly be approached through processes and knowledge of other fields of studies of the C.T.I.C. - such as Language, Mathematics, Natural Environment, Computers, Arts - accomplishing other objectives (Doliopoulou\&Sousloglou, 2007). Therefore, the concepts of S.S. are approached through the appropriately selected issues (Cross Thematic) and each theme can possibly be approached through activities from various fields of studies (interdisciplinary) by "illuminating" various aspects of them (Chrysafidis, 2009: 23-24; Sfyroera, 2002).

The sub-group Human Environment and Interaction consists of two smaller groups:

Group a: The child in the Kindergarten and its relationship with others. The corresponding objectives refer to the development of skills of socialization and inclusion in the social contexts (family, school, and neighborhood-village) in which it belongs. Emotional objectives are processed such as developing child self-esteem, awareness of its uniqueness as a person, objectives of perceiving and accepting the others as equal members of social groups and developing co-operation with them. Furthermore, social objectives are set and actions about child acquaintance with its close social environment and its micro-world are suggested which is particularly complex (e.g. individual differences, multiculturalism).Hence, the teacher being "aware of the complexity of the social context in which the child lives and develops" (Ministry of Education and Religious Affairs - P.I., 2002a:4) should utilize children's relevant experiences, their cultural background and help them develop their social skills. Tracing and respecting the differences among people of the same social context or among different social contexts is ventured through proper descriptions and comparisons.

Group b: The child in the broader human environment. It includes actions about the child being acquainted with its broader social environment in its historic and geographic dimension. It also includes efforts to make children understand the change of environment in time and space and 


\section{International Journal of Social Science and Economic Research}

ISSN: $2455-8834$

Volume:06, Issue:01 "January 2021"

approach technological achievements (e.g. Mass Media, transportation means, tools and machines of everyday life and occupations), the historical facts and persons as well as issues about understanding the social environment in its broader time - historic and spatial - and geographical dimensions (Ministry of Education and Religious Affairs - P.I., 2002a:4).

The next step is to study the competences related to S.S. which are expected to be developed by children through relevant suggested activities as stated in the Cross Thematic Integrated Curriculum for Kindergarten (Human environment and Interaction).

- The first objective is emotional and it refers to developing child self- esteem through achieving self-awareness. Children should be offered experiences of taking actions and initiatives along with assuming responsibilities in the framework of game and other organized activities (e.g. free participation in democratic discussion). Reference is made to the child's right to mistake, while its pedagogic handling is implied.

- The next objective is to develop social skills - competences such as communication and co-operation in the framework of free and organized activities, e.g. contacts, interviews with adults outside of school, inviting adults in school during the exploration of issues. As regards co-operation with peers, it commences by offering and accepting help to other children, a process that leads to the next objective, the development of a culture of cooperation among children through group work and joint discovery. Activities about group functioning, discussion of problems (conflicts, tensions) are suggested as they derive through co-operation, setting each one's personal limits and setting the rules of group and classroom function. Furthermore, contacts with adults outside of school are suggested (interviews with adults, inviting adults to school during the exploration of issues) (Jacobs \& Crowley, 2007).

- Contacting other people helps accomplish another important objective about understanding diversity meaning that children become aware of their uniqueness as persons with unique characteristics on the one hand (e.g. gender, competences, desires, culture) and of their similarity with the rest of the children in terms of personal aspects (e.g. needs, desires, emotions) on the other. In this framework, after having become aware of the concept of diversity, both in the close and broader environment, they begin to approach a more important concept that of equality among people as individual entities and values. They spot the differences (corporal, cultural, national, and religious with other people - suggested activities: listening to music of other cultures, trying the ethnic cuisine of other people). Furthermore, they accept the right to diversity, they are interested in the needs of other people due to their diversity (people with special needs, migrants, and children of the third world) and are sensitized in handling them. Composing groups of children from different cultural environments and different competences helps accept diversity. 


\section{International Journal of Social Science and Economic Research}

ISSN: $2455-8834$

Volume:06, Issue:01 "January 2021"

- Moreover, another objective is the knowledge of religious traditions pertaining to the Christian belief, worship and the corresponding customs explicitly tied to cultivating feelings of love and fellowship among all people and "towards all human beings on earth", highlighting, this way, the utmost message of Christianity, love to every human being and to the environment. At this point, Christian celebrations and the corresponding customs become the starting point of developing feelings of love to all people.

- Even though the previous objectives can be mostly characterized as social/emotional, since they refer to developing understanding and accepting the self and the others, our study is proof of the fact that there are a lot of objectives intensely characterized by the cognitive element (Ministry of Education and Religious Affairs - P.I., 2002b: 14).These are rules of hygiene, interaction between the person and the environment, understanding the historical time, geographical concepts and spatial skills. The cognitive nature of these objectives does not, of course, abolish their social dimension. On the contrary, in some cases, it may be favorable by cognitively supporting the accomplishment of social objectives, e.g. full comprehension of the chronological framework of an event can help develop deeper understanding of the meaning of this event.

The cognitive and social objectives can be better accomplished through activities which are mainly characterized by the linguistic communication of children through descriptions, comparisons, evaluations of facts, assumptions and argumentation. Using technological means such as cameras, tape recorders and computers does not only help approach the issues under discussion, but it also helpschildren perceive, albeit implicitly, the usefulness of technological means in an experiential manner (Martorella, 1994: 202-213; Pahl, 1996).

The suggested by the C.T.I.C. manner of processing S.S., at the same time one of its objectives, is by developing the competence of being familiarized with exploration through micro-surveys in order to answer the questions posed by the children about the issues under investigation (Martorella, 1994). The exploration begins by setting the question and trying to clarify it, it continues with making assumptions and gathering elements from different sources which are processed and interpreted in order to answer the initial question or to make new questions. It is noteworthy that exploration as a manner of studying orientates students to familiarizing with manners, strategies and methods so that they are able to find and discover information and answers by themselves. It should also be noted that this process helps cultivate their metacognitive skills since it helps them understand the way they learn and, therefore, become autonomous and independent learners.

\section{Conclusions}

Studying the C.T.I.C. for Kindergarten infers that S.S. offer the Kindergarten teachers the possibility to accomplish cognitive and social-emotional objectives through a variety of themes 


\section{International Journal of Social Science and Economic Research}

ISSN: $2455-8834$

Volume:06, Issue:01 "January 2021"

(Ministry of Education and Religious Affairs - P.I., 2002b: 14) relevant to formulating the child as an autonomous personality and a socialized citizen. In the first place, emphasis is placed on developing the competences of children to understand themselves and socialize in their close environment; processes of particular importance in S.S. programs (Koutsouvanou, 2002: 22-32). In this context, the discussion focuses on issues about human personality (e.g. desires, feelings, capacities and characteristics), their differentiations and the basic similarities among people as well as their relationships with others. There are also particularly important objectives regarding diversity and they introduce intercultural education and the corresponding human sensitization to the needs of the contemporary society (Pantazis, 2006: 36-49; Martorella, 1994: 247-261).

The S.S. program included in the C.T.I.C. offers an array of possibilities about the development of child personality, their socialization, and the discussion of political (Oikonomidis, 2009; Seefeldt, 2005), historic (O’Hara \& O’Hara, 2001), geographical, religious and social (Koutsouvanou, 2002) issues conducive to shaping active citizens (Michelli, 2005). This is a quite enriched and broad program, open to themes and issues of the contemporary Greek society. We strongly believe that by approaching relevant issues, based on the C.T.I.C. objectives, the specific objectives of the program, namely preserving national identity, developing democratic identity, acceptance and respect to diversity are also accomplished (C.T.I.C. - P.I., 2002b: 5).

The possibility of Cross Thematic and interdisciplinary approach of S.S. of every relevant theme is proof of the association of S.S. with the broader social life as well as their relation to other sciences as they holistically approach each issue (Karagiorgos, 2005). All these activities implemented in school through modern methodological approaches (collaborative, participatory, experiential and cross thematic projects) along with the new objectives of the Curricula are conducive to making students competent in managing and handling complicated dilemmas of social and moral content which often occur in their personal and social life.

This way, students are shaped into the citizens of tomorrow: active, democratic, responsible, participatory, voicing their opinion and playing their role in everyday situations along with being respectful and accepting the other whom they will get to know. They will also be able to understand their role, rights and obligations within an organized and democratically operated school classroom, school community and society (Eleftherakis, 2011). All the suggestions of the Curricula of the Greek school and Kindergarten, though not explicitly suggested but implied, about the creation of a democratic school, or else a democratic hive, in which democratic personalities will be shaped, support the idea that problems need to be surmounted, while teachers, parents and the entire society should not be complacent.

Some of these problems and distortions are listed below for further consideration and investigation: 


\section{International Journal of Social Science and Economic Research}

ISSN: $2455-8834$

Volume:06, Issue:01 "January 2021"

a. The interests of some people and groups

$b$. Lacking proper education and continuous training of teachers because the project is, indeed, a complex process and it needs in advance group preparation

c. Material-congested and highly instructional and condensed Curricula and C.T.I.C.; however, not in Kindergarten so much

d. Lack of coordination in education in terms of objectives, methods, manners of evaluation in all levels and grades (Kindergarten, Primary School, High School, Lyceum, University Exams).

All in all, the Cross Thematic Integrated Curriculum for Kindergarten along with the Program for Planning and Developing Activities, can make teaching in the Kindergarten more freely formulated because there are set objectives and suggested activities;yet, their implementation is not mandatory. Nevertheless, the habits and tradition of the elder teachers (erroneous school and social cultures, biases and stereotypes, distortions, obsessions, compulsions), such as the cognitive reproductive objectives setting (cognitive-centered, memorizing, static and of small self-actualization school, lack of democracy, etc.)are deep-rootedand create obstacles and retrogressions to the new curricula. All the above stated, strongly inscribed in people's memory and beliefs, are eventually considered a rationale and unscrupulous practice that hinders the new perspective of the new Cross Thematic Integrated Curriculum to gain ground even in Kindergarten. In this educational grade, which, due to its nature, is more open to the new perspective of cross thematic, an approach of knowledge is expected by every sensible and democratically sensitive person, that enables the accomplishment of cognitive, but mainly emotional, social and political objectives of the new, democratic, intercultural and equal opportunities school that could eventually include all students and provide them with knowledge, skills, attitudes and values suggested by the new curriculum.

\section{References}

Allen, R. (1996). "Introduction: What should we teach in Social Studies and why?" In B. Massialas\& R. Allen (Eds.) Crucial Issues in TeachingSocial Studies K-12. Belmont: Wadsworth.

Bourdieu, P., Passeron, J. C. (1976). Reproduction in education, society and culture. London: Sage.

Bourdieu, P., Passeron, J.-C. (1993). The heirs: university students and culture. Athens: InstituteofBook - M. Kardamitsas. (translated in Greek). 


\section{International Journal of Social Science and Economic Research}

ISSN: $2455-8834$

Volume:06, Issue:01 "January 2021"

Bourdieu, P., Passeron, J.-C. (2014).The reproduction. Elements for a theory of the education system. Athens: Alexandreia. (translatedinGreek).

Chrysafidis, K. (2006). Experiential-communicative teaching. Athens: Gutenberg. (In Greek).

Chrysafidis, K. (2009). Cross thematic curricular approach. Athens: Diptyxo. (In Greek).

D’ Addesio, J., Grob, B., Furman, L., Hayes, K. \& David, J. (2005). Learning about the world around us. Young Children, 60(5), 50-57.

Dafermou, Ch., Koulouri, P. \&Basagianni, E. Ministry of Education and Religious Affairs - P. I. (2006). The Guide of the Kindergarten Teacher. Educational Plannings. Creative Learning Environments. Athens: O.E.D.B. (in Greek).

Doliopoulou, E. \&Sousloglou, K. (2007). Kindergarten teachers' views about the implementation of C.T.I.C. for Kindergarten. Exploring the World of Child, 7, 123-149. (In Greek).

Eleftherakis, Th. (2011). Political socialization and Education. In V. Oikonomidis\& Th. Eleftherakis (Eds.). Education, Democracy and Human Rights. Athens: Diadrasi, $2^{\text {nd }}$ ed., pp.48-100. (In Greek).

Feldman, R. (2007). Development Across the Life Span (5th Edition). New Jersey: Prentice Hall.

Husen, T. (1975). Social Influences on Educational Attainment: Research Perspectives on Educational Equality. Published by Organization for Economic Cooperation \& Development.

Jacobs, G. \& Crowley, K. (2007). Play, Projects and Preschool Standards. Thousand Oaks, CAQ Corwin Press.

Karagiorgos, D. (2005). InM. Kassotakis\& G. Flouris (Eds.). Educational Analects. Honorary Volume to Vyronas G. Massialas. Athens: Atrapos, pp. 694-723. (In Greek).

Kitsaras, G. (1998). Preschool Education Programs. Rethymno: author's publication. (In Greek).

Koutsouvanou, E. (2002). Social Studies in Preschool Education. Athens: Odysseus 4th ed. (In Greek).

Kyridis, A. (1996). A sociological approach to preschool education. Thessaloniki: Kyriakidis Bros. (In Greek).

Martorella, Peter. (1994). Social Studies for Elementary School Children. Developing Young Citizens. New Jersey: Merrill. 


\section{International Journal of Social Science and Economic Research}

ISSN: $2455-8834$

Volume:06, Issue:01 "January 2021"

Michelli, N. (2005). Education for democracy: what can it be? In Michelli, N. \& Keiser, D. L. (Eds.), Teacher Education for Democracy and Social Justice. New York: Routledge, 330 .

Ministry of Education and Religious Affairs - Pedagogical Institute (M.E.R.A. - P.I.) (2002a). Cross Thematic Integrated Curriculum for Kindergarten.Athens: P.I.

Ministry of Education and Religious Affairs - Pedagogical Institute (M.E.R.A. - P.I.) (2002b). Cross Thematic Integrated Curriculum for Elementary and High School.Athens: P.I.

Nikolaou, S.-M. (2009). Theoretical issues in Sociology of Education. Athens: Gutenberg. (In Greek).

O’ Hara, L. \& O’ Hara, M. (2001). Teaching History 3-11. The essential guide. London: Continuum.

Oikonomidis, V. (2009). Educating democratic citizens in the Kindergarten. In V. Oikonomidis, \& Th. Eleftherakis (Eds.), Education, Democracy and Human Rights (pp. 204-246). Athens: Atrapos. (In Greek).

Pahl, R. (1996). Digital technology and Social Studies. In B. Massialas\& R. Allen (Eds.) Crucial Issues in TeachingSocial Studies $K-12$. Belmont: Wadsworth.

Pantazis, S. (2006). Intercultural Education in Kindergarten. Athens: Atrapos. (In Greek).

Parsons, T. (1964). Social Structure and Personality. New York: Free Press.

Seefeldt, C. (2005). How to Work with Standards in the Early Childhood Classroom. New York: Teachers College Press.

Sfyroera, M. (2002). Cross Thematic Approach to Knowledge. Athens: Ministry of Education and Religious Affairs - University of Athens. Education of the Muslim Children Kleidia kai Antikleidia. (In Greek).

Spodek, B. (1969). Developing Social Science concepts in the Kindergarten. In W. Herman (Ed.). Current Research in Elementary School Social Studies. Toronto: Macmillan.

Walmsley, B. B. \& Wing, D. R. (2004). Welcome to Kindergarten. A Month by Month Guide to Teaching and Learning. NH: Portsmouth.

Zacharenakis, K. (1991). CompensatoryEducation. Athens: author'spublication. (InGreek). 